\title{
A RERA by Any Other Name...
}

\author{
Barry Krakow, M.D. ${ }^{1,2,3}$; Victor A. Ulibarri, B.A. ${ }^{1,2}$; Natalia D. Mclver, B.A. ${ }^{1,2}$ \\ ${ }^{1}$ Sleep \& Human Health Institute, Albuquerque, NM ; ${ }^{2}$ Maimonides Sleep Arts \& Sciences, Ltd, Albuquerque, NM; \\ ${ }^{3}$ Los Alamos Medical Center, Los Alamos, NM
}

W e empathize with the head spinning Dr. Masi experienced, ${ }^{1}$ triggered by the paradoxical views recently expressed in the Journal. ${ }^{2,3,4}$ Although Dr. Masi defined the problem as one between "lumpers" and "splitters," we prefer a narrower dichotomy contrasting libertarians and anarchists, the former wanting really small government, the latter wanting none. In the current breathing paradox, everyone strives for the smallest AHI during a titration PSG, but some strive to eliminate nearly all pathological breathing events (e.g., RDI $<5$ ), because evidence demonstrates treating RERAs (breathing events closely associated with UARS) with positive airway pressure therapy yields further improvement in clinical outcomes. ${ }^{5}$

From this perspective, it is our opinion Sutherland et al.'s work begs the question to what degree should we reduce breathing events. Their update on oral appliance therapy (OAT) seems only to account for residual apneas and hypopneas or AHI without mention of RERAs or RDI as defined by the AASM. ${ }^{4}$ Moreover, since 2008 AASM clinical guidelines mandated aggressive treatment (i.e., elimination) of RERAs during titrations. ${ }^{6}$ Sutherland et al. do not seem to reconcile these guidelines with OAT use in the sleep lab, albeit newer devices will possess capacity for in vivo adjustments. ${ }^{4}$ Regardless, until evidence demonstrates OAT-related reductions in RERAs, how are these devices first-line therapy? ${ }^{4}$

We wholeheartedly concur with Sutherland et al. that some OSA treatment is better than none. ${ }^{4}$ In context, OAT is an outstanding alternative for patients who reject or cannot tolerate PAP therapy. Our strong endorsement of OAT is tempered, however, by residual RERAs commonly observed in such patients returning for retesting to measure treatment efficacy. Sutherland et al. aptly point out the lack of evidence on OAT retesting, ${ }^{4}$ which could prove informative in managing residual breathing events. Residual RERAs are also seen among OSA patients with or without clear-cut symptom deterioration when returning for re-titration studies after months or years of PAP use. ${ }^{7}$ For returning patients without overt symptom decline, we often see the "ceiling effect": a cognitive default, leading to comparisons between their new state of sleep health and their past symptom load, coupled with the inability to imagine further potential improvements that may ensue by tweaking their OAT or PAP device. Explaining the "ceiling effect" motivates patients to move forward with re-titrations to adjust pressures per AASM guidelines. By attempting to eliminate all breathing events including RERAs, we seek to normalize the airflow curve, ${ }^{7}$ after which outcomes improve.

If normalizing the airflow curve is a prudent step, what is normal? AASM guidelines imply normal is virtually no breathing events, but Condos el al.'s work supports a more precise construct: a fully rounded airflow curve on inspiration. ${ }^{8}$ This approach has shaped our clinical practice for years, from which we would offer a new comment and a few questions regarding Dr. Collop's premise that acceptance of the 1A Hypopnea definition (i.e., 30\% flattening of airflow signal with arousal) will subsume flow limitation events (RERAs) into the hypopnea category and thus resolve diagnostic dilemmas sleep centers face with certain insurance carriers. ${ }^{2}$ We concur in large measure with Dr. Collop; however, on a titration neither the use of OAT nor this newer scoring principle addresses the finding of persistent flattening, ${ }^{8}$ which by manifesting as less than a $30 \%$ drop on the airflow signal meets no criteria for any definition of hypopnea. Still, we accept flattening is in the eye of the beholder or in an eye influenced by variations in high filter settings.

While there may be a practical solution for some diagnostic studies, persistent inspiratory flattening on titrations remains a problem. As in our commentary, what is the policy towards a Medicare PAP user presenting with residual sleepiness likely due to persistent flattening $?^{3}$ Would we need special authorization to conduct a retitration? Would we still be required to eliminate the flattening per AASM? Would we be reimbursed for the study if it only showed residual RERAs? And, how do we explain these nuanced points to a patient who is cognitively impaired due to residual sleepiness? One wonders whether or not Medicare intended to assert this much influence over what our patients experience in the bedroom. It seems doubtful a government institution intended to hinder sleep professionals from normalizing the airflow curve of their beneficiaries. Common sense provides clear answers to these questions; whereas Medicare policy remains ambiguous. 
In sum, it appears to us Sutherland et al. were addressing for the most part a cost-effectiveness issue, ${ }^{4}$ and their points were clearly made and highly relevant; whereas, we sought to emphasize the benefits of titrating RERAs as an efficacy issue. ${ }^{3}$ Although we recognize our RERA zealotry seems like counting angels on the head of pin, we are not suggesting a "War on RERAs" will improve the Gross Domestic Product. ${ }^{9}$ However, on a case-by-case basis, we are impressed that aggressive treatment of RERAs further reduces sleepiness, insomnia, and fatigue in a larger proportion of sleep apnea patients than may be currently appreciated by some sleep professionals as well as some insurance carriers. Science will continue to explore this proposition, and to quote Dr. Collop, we too would like to see "...science determine the right care for patients."

\section{CITATION}

Krakow B, Ulibarri VA, Mclver ND. A RERA by any other name. J Clin Sleep Med 2014;10(6):703-704.

\section{REFERENCES}

1. Masi AM. The lumpers and splitters paradox. J Clin Sleep Med 2014;10:701.

2. Collop N. Breathing related arousals: call them what you want, but please count them. J Clin Sleep Med 2014;10:125-126.

3. Krakow B, Krakow J, Ulibarri VA, Mclver ND. Frequency and accuracy of "RERA" and "RDI" terms in the Journal of Clinical Sleep Medicine from 2006 through 2012. J Clin Sleep Med 2014;10:121-4.

4. Sutherland $\mathrm{K}$, Vanderveken $\mathrm{OM}$, Tsuda $\mathrm{H}$, et al. Oral appliance treatment for obstructive sleep apnea: an update. J Clin Sleep Med 2014;10:215-27.
5. Exar EN, Collop NA. The upper airway resistance syndrome. Chest 1999;115:1127-39.

6. Kushida CA, Chediak A, Berry RB, et al. Clinical guidelines for the manual titration of positive airway pressure in patients with obstructive sleep apnea. $J$ Clin Sleep Med 2008;4:157-71.

7. Krakow B, Ulibarri VA, Romero EA, Thomas RJ, Mclver ND. Adaptive servoventilation therapy in a case series of patients with co-morbid insomnia and sleep apnea. J Sleep Disord Treat Care 2013;2:1-10.

8. Condos R, Norman RG, Krishnasamy I, Peduzzi N, Goldring RM, Rapoport DM. Flow limitation as a noninvasive assessment of residual upper-airway resistance during continuous positive airway pressure therapy of obstructive sleep apnea. Am Respir Crit Care Med. 1994;150:475-80.

9. Mullainathan S. Get Some Sleep, and Wake Up the G.D.P. The New York Times. February 1, 2014. Available at: http://www.nytimes.com/2014/02/02/business/ get-some-sleep-and-wake-up-the-gdp.html.

\section{SUBMISSION \& CORRESPONDENCE INFORMATION}

\section{Submitted for publication May, 2014}

\section{Accepted for publication May, 2014}

Address correspondence to: Barry Krakow, M.D., Sleep \& Human Health Institute, 6739 Academy N.E., Suite 380, Albuquerque, NM 87109; Tel: (505) 998-7204; Fax:

(505) 998-7220; E-mail: bkrakow@sleeptreatment.com

\section{DISCLOSURE STATEMENT}

Dr. Krakow operates websites providing education and offering products and services for sleep disorder patients, he markets and sells books for sleep disorder patients, he owns and operates a commercial sleep institute, and is the president of a nonprofit sleep research institute which has received support from Respironics, Simon Foundation, and Oxnard Foundation. He has consulted for Classic Sleepcare and was an unsalaried principal investigator for Sleep and Human Health Institute. The other authors have indicated no financial conflicts of interest. 